\title{
Changes of cytokine levels in a mouse model of post-infectious irritable bowel syndrome
}

\author{
Bo Yang ${ }^{1}$, Xuchun Zhou ${ }^{1 *}$ and Cheng Lan ${ }^{2}$
}

\begin{abstract}
Background: Irritable bowel syndrome (IBS) is a highly prevalent functional gastrointestinal disorder. Post-infectious IBS (PI-IBS) is caused by an acute gastrointestinal infection preceding the onset of symptoms. However, the pathophysiology of PI-IBS is not clear, and the purpose of this study was to investigate the probable immune mechanisms of PI-IBS.

Methods: C57BL/6 mice were randomly assigned to either an infection group or a control group. Mice in the infection group were infected with Trichinella spiralis to establish a model of PI-IBS (500 Trichinella), while control mice received only salt solution. Visceral sensitivity of colorectal distention in mice was evaluated by abdominal withdrawal reflex scores and intestinal inflammation was assessed using hematoxylin-eosin staining; at day 56 post-infection, the mRNA and protein levels of specific cytokines in the gut segments were detected using reverse-transcription polymerase chain reaction and enzyme-linked immunoabsorbent assay.
\end{abstract}

Results: Levels of interferon $\gamma$ and interleukin (IL)-17 in the PI-IBS group were significantly increased in the duodenum and ileum, and IL-10 was decreased in the jejunum, ileum, and colon compared with control mice. However, the expression level of IL-1 $\beta$ was not significantly different between the two groups.

Conclusions: The present study suggests that the local low-grade inflammation and immune activation that are an important component of the pathophysiology of PI-IBS are primarily induced and maintained by specific cytokines.

Keywords: Post-infectious irritable bowel syndrome, IL-1ß, IFN- $\gamma$, IL-10, IL-17

\section{Background}

Irritable bowel syndrome (IBS) is a highly prevalent functional gastrointestinal disorder characterized by abdominal pain and alterations in bowel habits [1]. Between $3.7 \%$ and $36 \%$ of patients with acute gastrointestinal infection subsequently develop a form of IBS known as post-infectious IBS (PI-IBS) [2].

Many pathogens can cause PI-IBS. Bacteria and parasites are often used in PI-IBS animal models; however, for bacterially-induced PI-IBS animal models, the major characteristics of IBS such as visceral hypersensitivity, alterations in motility and secretion are weak or sometimes absent, and it therefore remains controversial whether bacterial infection results in a valid model of PI-IBS. Nippostrongylus brasiliensis and Cryptosporidium parvum have been used in rat models of PI-IBS. However, it was found that models infected by $N$. brasiliensis lacked

\footnotetext{
*Correspondence: chqxchzh@163.com

'Department of Gastroenterology, The First Affiliated Hospital of Chongqing Medical University, Chongqing 4000 16, China

Full list of author information is available at the end of the article
}

visceral sensitivity. The features of IBS such as motility dysfunction and altered secretion have not been evaluated in the C. parvum infection model [3]. Infection by Trichinella spiralis larvae induced changes in visceral sensitivity, alterations of intestinal smooth muscle function, and altered secretion. These abnormalities persisted after animals recovered from infection, suggesting that this is a suitable model of PI-IBS $[4,5]$.

The pathophysiology of PI-IBS is not fully understood, but low-grade inflammation and chronic alteration of the immune system at the molecular level have been shown to be associated with mucosal secretory function, and with smooth muscle and enteric nervous fibers [6-8]. In particular, an imbalance of pro- and antiinflammatory cytokines is seen, which may play a key role in the local intestinal inflammation.

A number of reports related to PI-IBS patients have found a clear increase in many immune cell types within the mucosa [9-15]. Various animal models have been developed to gain insight into the underlying mechanism 
of IBS. A large number of studies have demonstrated that certain indicators, such as visceral hypersensitivity and persistent dysfunction of the intestinal muscle, exist in mice infected with $T$. spiralis $[4,16,17]$. In fact, the inflammatory response to intestinal parasites has been regarded as a representative defense response against pathogens. For this reason, experimental infection with the parasite Trichinella has been widely used to establish models for detecting the pathogenesis of intestinal dysfunction $[18,19]$. Activated immune cells continue to release various cytokines after an acute intestinal infection [20], for example, T-helper (Th) cells produce interferon (IFN)- $\gamma$ and interleukin (IL)- $1 \beta$ to promote the inflammatory response; T-regulatory cells release IL-10 to prevent autoimmunity; in contrast, IL-17, which is produced by Th17 cells, can induce autoimmunity [20]. These cytokines may alter the physiology and immunity of the host gut to cause symptoms of PI-IBS: IL-1 $\beta$ activates nitric oxide synthase and enkephalin immunoreactivity on interneurons or motorneurons and suppresses presynaptic cholinergic neurotransmission [21,22]. Moreover, IL-1 $\beta$ can stimulate cecocolonic motor activity and cause a migrating myoelectric complex pattern in the small intestine [23]. IFN- $\gamma$ and IL-1 $\beta$ can disrupt the colonic epithelial barrier and increase intestinal tight junction permeability [24-26]; reduction of IL-10 may cause an imbalance between pro- and anti-inflammatory mechanisms, resulting in chronic intestinal inflammation [27]. IL-17 and IFN- $\gamma$ can act cooperatively in the promotion of inflammatory responses in the intestinal mucosa [28]. Hence, in this study, we established a PI-IBS mouse model and assessed local expression levels of a range of cytokines in different intestinal segments in order to investigate the probable immune mechanisms of PI-IBS.

\section{Methods \\ Animals}

Studies were performed on specific pathogen-free female C57L/B6 mice, 4-6 weeks old, obtained from the Animal Center of Chongqing Medical University. The experimental procedure was approved by the Animal Welfare committee of Chongqing Medical University, China. A total of 34 mice were randomly assigned to either a control group $(n=17)$ or a PI-IBS group $(n=17)$ and maintained under controlled conditions with 12-h light/dark cycle.

\section{Trichinella infection}

Infective larvae were obtained from muscle of C57L/B6 mice infected with Trichinella at least 30 days in advance. The infected mice were humanely sacrificed, skinned, and eviscerated, and the muscles containing encysted larvae were minced and digested in $1 \%$ pepsin A (Biosharp, China) and $1 \% \mathrm{HCl}$ at $37^{\circ} \mathrm{C}$ for 16 hours. The isolated infective larvae were washed several times with $0.85 \% \mathrm{NaCl}$ and suspended in balanced salt solution. Mice in the PI-IBS group were infected by the oral administration of 350-400 larvae in $0.2 \mathrm{ml}$ of solution, while mice in the control group received the same volume of physiological saline [11].

\section{Sample collection and processing}

Three mice from each group were humanely sacrificed (ether inhalation and cervical dislocation) on day 14, 28 and 56 post-infection (PI). Intestinal samples taken from the duodenum $(10 \mathrm{~cm}$ distal to the pylorus), jejunum (20 cm distal to the pylorus), ileum $(30 \mathrm{~cm}$ distal to the pylorus) and colon (distal to the caecum) were flushed with physiological saline to remove gut contents. A $1 \mathrm{~cm}$ long sample from each intestinal tissue was fixed overnight in $4 \%$ paraformaldehyde and embedded in paraffin for histological analysis. The rest of the intestine tissue was immediately preserved in liquid nitrogen for subsequent RNA extraction and protein assay.

\section{AWR scores}

Visceral hyperalgesia to colorectal distention was assessed at day 56 PI by abdominal withdrawal reflex (AWR) [29]. Mice were briefly anesthetized with ether, and a balloon catheter (6-Fr, $2 \mathrm{~mm}$ external diameter) was inserted rectally into the descending colon of mildly sedated mice. After waking up and adapting for $1 \mathrm{~h}$, colorectal distention was performed in a stepwise fashion. Each 20-second distention was followed by a 30-second resting period. Each level of distention $(0.25,0.35,0.5$, and $0.65 \mathrm{ml})$ was repeated three times, and the balloon was deflated and withdrawn after assessing AWR. The AWR score was assigned as follows: 0 , no behavioral response to colorectal distention; 1 , brief head movement followed by immobility; 2 , contraction of abdominal muscles; 3 , lifting of abdomen; 4 , body arching and lifting of pelvic structures [30].

\section{Histological analysis}

Paraffin-embedded tissues were cut into 5 - $\mu$ m-thick sections. To deparaffinize, the sections were immersed in xylene at $56^{\circ} \mathrm{C}$ twice for $20 \mathrm{~min}$, and hydrated with ethanol (twice with $100 \%$, once with $95 \%$, and once with $75 \%$ ethanol) for $5 \mathrm{~min}$. The sections collected at the selected time points (14, 28 and 56 days PI in two mice from each group), were processed routinely for hematoxylin and eosin (H\&E) histology. H\&E-stained slides were evaluated in a blinded fashion by two independent investigators. A histopathological score was assigned as described by Dieleman [31].

\section{RT-PCR mRNA assay}

Total RNA from the intestinal mucosa was extracted using Trizol solution (Takara, Japan). The expression of cytokine genes was assayed using reverse-transcriptase 
polymerase chain reaction (RT-PCR). The $\beta$-actin (Actb) mRNA level was used as an internal reference, and levels of mRNA expression were quantitated by optical densitometry after electrophoresis on an agarose gel. All primers are listed in Table 1 . The reverse transcription was conducted at $37^{\circ} \mathrm{C}$ for $15 \mathrm{~min}, 95^{\circ} \mathrm{C} 5 \mathrm{sec}$. The PCR cycling condition was 36 cycles at $94^{\circ} \mathrm{C}$ for $40 \mathrm{sec}$, $55^{\circ} \mathrm{C}$ (Illo and $\left.I l 1 b\right), 57^{\circ} \mathrm{C}$ (Ill17 and Ifng) or $59^{\circ} \mathrm{C}$ (Actb) for $30 \mathrm{sec}$ and $72^{\circ} \mathrm{C}$ for $35 \mathrm{sec}$. The PCR end products were run on a $5 \%$ agarose gel and stained with ethidium bromide. The gray values of the bands were calculated using quantity one software (Bio-Rad, America). The relative mRNA expression levels of the target genes were normalized to the corresponding internal standard.

\section{Intestine homogenate and ELISA}

For enzyme-linked immunoabsorbent assay (ELISA) [32], all of the intestinal segments were processed using an ultrasonic disrupter (Bandelin, Germany) and homogenized in RIPA buffer (Takara, Japan). The homogenates were then centrifuged at $10000 \mathrm{rpm}$ for $20 \mathrm{~min}$, and protein concentrations in the supernatant of homogenates were determined using a BCA protein assay kit (Beyotime, China). Levels of tissue cytokines were assayed using mouse IL-1 $\beta$, IL-10, IL-17, and IFN- $\gamma$ ELISA kits (Boster, China) according to the manufacturer's protocols.

\section{Statistical analysis}

Statistical analysis was performed using SPSS 19.0 software. Values are presented as mean \pm standard deviation (SD). The independent sample $t$ test was used to compare the results between the two groups. A value of $P<0.05$ was accepted as statistically significant.

\section{Results}

AWR scores

AWR scores in the PI-IBS group were significantly higher than those in the control group at distention

Table 1 RT-PCR primer sequences

\begin{tabular}{|c|c|}
\hline Cytokines & Primer sequence \\
\hline \multirow[t]{2}{*}{ I/1b (94 bp) } & Forward 5'-ATGGGCAACCACTTACCTATTT—3' \\
\hline & Reverse 5'-GTTCTAGAGAGTGCTGCCTAATG—3' \\
\hline \multirow[t]{2}{*}{ //10 (116 bp) } & Forward 5'-ACAGCCGGGAAGACAATAAC-3' \\
\hline & Reverse 5'—CAGCTGGTCCTITGTTTGAAAG—-3' \\
\hline \multirow[t]{2}{*}{ //17 (123bp) } & Forward 5'-CGCAATGAAGACCCTGATAGAT—3' \\
\hline & Reverse 5'-CTCTTGCTGGATGAGAACAGAA-3' \\
\hline \multirow[t]{2}{*}{ Ifng (128 bp) } & Forward 5'-AAATCCTGCAGAGCCAGATTAT—3' \\
\hline & Reverse 5'-GCTGTTGCTGAAGAAGGTAGTA-3' \\
\hline \multirow[t]{2}{*}{ Actb (470 bp) } & Forward 5'-AGGCTGTGCTGTCCCTGTATG_-3' \\
\hline & Reverse 5'-GAGGTCTTTACGGATGTCAACG-3' \\
\hline
\end{tabular}

volumes of 0.35 and $0.5 \mathrm{ml}(P<0.01)$. However, there were no significant differences at volumes of 0.25 or $0.65 \mathrm{ml}(P>0.05)$. This was because distention at a volume of $0.25 \mathrm{ml}$ was too slight to reach the minimum threshold pressure of abdominal muscle contraction, whereas distention at a volume of $0.65 \mathrm{ml}$ was so strong that it led to a very intense response in mice of both groups (Table 2).

\section{Histological analysis}

H\&E staining of the ileum and colon showed a marked infiltration by neutrophils in the lamina propria and interstitial edema on day 14 PI. Infiltration and edema gradually reduced from day 14 PI until day 56 PI, at which stage no obvious inflammatory infiltrate was observed (Figure 1).

\section{ELISA}

The localized expression of IL-1 $\beta$, IL-10, IL-17, and IFN- $\gamma$ protein in the intestine was assayed using the corresponding ELISA kits. As shown in Figure 2, expression of IL-10 in jejunum, ileum and colon was much lower in the PI-IBS group than that in control group (all $P<0.05$ ). In contrast, compared with control mice, the concentrations of IL-17 and IFN- $\gamma$ in the duodenum and ileum of PI-IBS mice were significantly higher (all $P<0.05$ ). However, the concentration of IL-1 $\beta$ showed no noticeable differences in any of the intestinal segments between the two treatment groups.

\section{RT-PCR mRNA assay}

Il10 levels in the jejunum, ileum, and colon segments were significantly lower in the PI-IBS group than those in control group (all $P<0.05$ ). For Il17 and Ifng levels, those in the duodenum and ileum were notably higher in PI-IBS mice compared with control mice (all $P<0.05$ ). However, the Illb mRNA levels were not significantly different between the two groups (Figure 3).

\section{Discussion}

Eight weeks after T. spiralis infection, the GI system still had disturbed visceral hypersensitivity without any histological evidence of intestinal inflammation. This means that the $T$. spiralis infection model is an acceptable model to represent PI-IBS [33]. AWR scores were altered in response to low or medium pressures, but did

Table 2 AWR scores for colon distention in mice in the
PI-IBS and control groups $(\overline{\mathbf{x}} \pm \mathbf{s})$
\begin{tabular}{llllll}
\hline Groups & $\mathbf{n}$ & \multicolumn{4}{l}{ Volume of colon distention } \\
\cline { 3 - 6 } & & $\mathbf{0 . 2 5} \mathbf{~ m l}$ & $\mathbf{0 . 3 5} \mathbf{~ m l}$ & $\mathbf{0 . 5} \mathbf{~ m l}$ & $\mathbf{0 . 6 5} \mathbf{~ m l}$ \\
\hline PI-IBS & 8 & $0.50 \pm 0.25$ & $2.42 \pm 0.24^{* *}$ & $3.54 \pm 0.31^{* *}$ & $3.88 \pm 0.35$ \\
Control & 8 & $0.33 \pm 0.31$ & $1.83 \pm 0.44$ & $2.92 \pm 0.43$ & $3.75 \pm 0.46$ \\
\hline All data
\end{tabular}

All data are presented as the mean $\pm S D$. ${ }^{* *} P<0.01$ compared with the control group. 


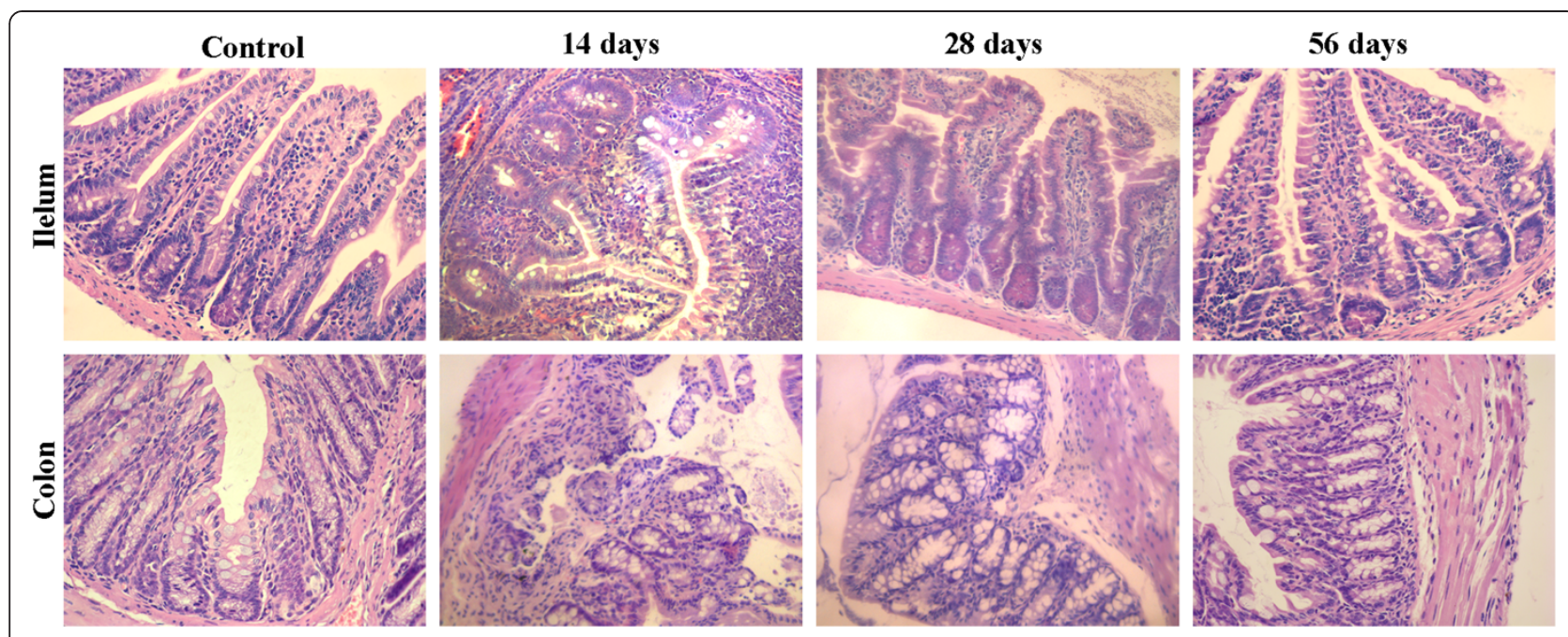

Figure 1 Histological analysis of intestinal tissue samples. Sections of ileum and colon from control or infected (at 14,28, or 56 days Pl, $n=3$ ) mice were stained with hematoxylin and eosin $(H \& E)$. Original magnification $\times 200$.

not significantly differ from healthy mice at high pressure. This indicates that the low/medium threshold nerves, but not the high threshold nerves, are altered. This may be related to different mechanical stimulation activated by different pressure expansion [34]. When distention volume was $0.25 \mathrm{ml}$, the pressure was too low to cause any visceral sensation. When the distention volume was $0.65 \mathrm{ml}$ (high pressure), the level of stimulation was so high that it resulted in a very intense response in both groups of mice. When the distention volume was either 0.35 or $0.5 \mathrm{ml}$, the AWR scores in the model group were higher than those in the control group, and the pain threshold in the model group was lower than that in the control group at the same time point. This suggests an increase of the visceral sensitivity in mice after infection. Although the pathogenesis of PI-IBS is not well understood, increasing evidence suggests that low-grade inflammation and immune activation play a pivotal role in the occurrence and persistence of its symptoms [35-40]. Several reports have described high numbers of $\mathrm{T}$ cells in various lymphoid compartments of the small or large intestine in IBS patients $[9,10,41]$, and activated $\mathrm{T}$ cells produce many cytokines involved in the inflammatory process, including IL-1 $\beta$, IL-10, IL-17, and IFN- $\gamma$. Further studies have shown that chronic alterations of inflammatory cytokines are found in the peripheral blood and intestinal mucosa, which is consistent with the development of IBS symptoms at the molecular level $[20,37]$. However, alterations of certain cytokines in different locations within the GI tract have not been systematically reported in PI-IBS.

In the present study, we successfully established a PIIBS mouse model induced by Trichinella larvae and found that the levels of IFN- $\gamma$, as well as IL-17, were increased in the duodenum and ileum. IFN- $\gamma$ is a classical pro-inflammatory cytokine, which can act cooperatively with IL-17 in the promotion and shaping of inflammatory responses in the intestinal mucosa [28], and also can be regulated by IL-17 to drive neutrophil migration and mediate tissue injury [42-44]. Moreover, the high expression of IFN- $\gamma$ could inhibit IL-10 production [45], consistent with our results showing that IL-10 levels were decreased in jejunum and ileum. In addition, IFN- $\gamma$ can disrupt the colonic epithelial barrier and increase intestinal tight junction permeability [24-26]. Many mechanisms have been proposed for this phenomenon,
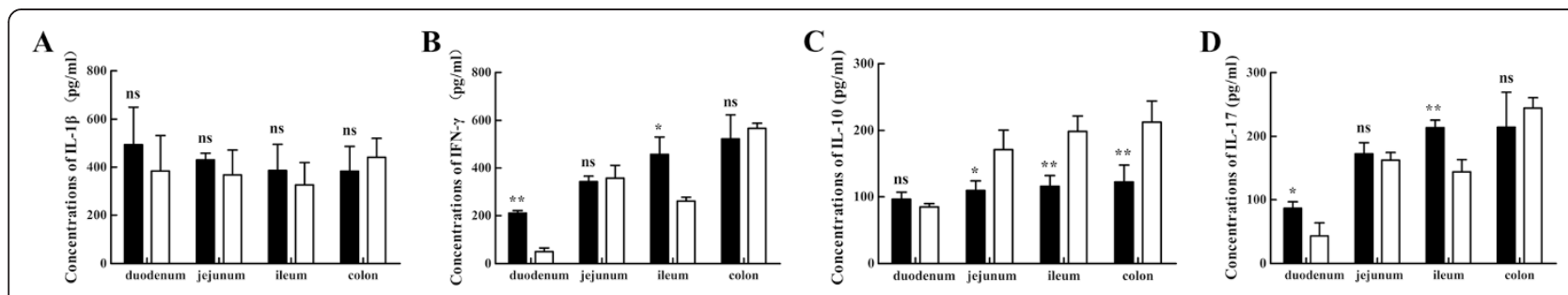

Figure 2 Concentrations of IL-1 $\beta$ (A), IL-10 (B), IL-17 (C), and IFN- $\gamma$ (D) protein in the different intestinal segments in the PI-IBS ( $n=8$ ) and control $(\mathbf{n}=\mathbf{8})$ groups. Black: PI-IBS group, white: control group. Data are presented as mean \pm SD. ${ }^{*} P<0.05$, ${ }^{*} P<0.01$ versus control group. 


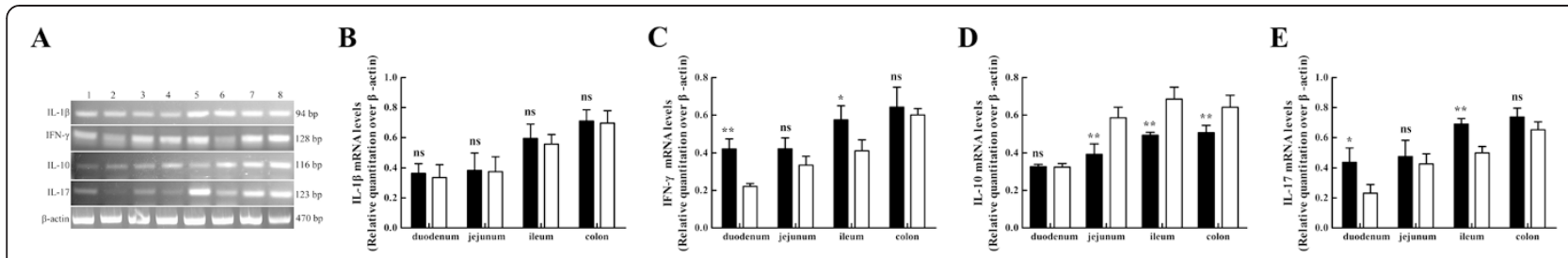

Figure 3 The mRNA levels of $I / 1 b(B), I I 10(C), I I 17(D)$, and Ifng (E) in different intestinal segments in the PI-IBS $(n=8)$ and control $(n=8)$ groups. A. Representative graphs of the PCR assay. Lanes 1, 3, 5, and 7 are duodenum, jejunum, ileum and colon of the PI-IBS group, respectively; lanes 2 , 4,6 , and 8 are duodenum, jejunum, ileum and colon of the control group, respectively. Black: PI-IBS group, white: control group. Date are presented as mean $\pm \mathrm{SD}$. $* P<0.05,{ }^{*} P<0.01$ versus control group.

including dysbiosis and elimination of Paneth cells [46]. Proliferation of intestinal epithelial cells is inhibited through suppression of $\beta$-catenin/T cell factor signaling [47], and the AMPK signaling pathway is activated by phosphorylation [48]. IL-17, which plays a protective role in infections, exhibits its inflammatory effects by activating NF-kB, MAPKs and C/EBP cascades to induce the production of multiple pro-inflammatory molecules and subsequent activation of macrophages and neutrophils [49]. It also has a regulatory function limiting the accumulation and activity of neutrophils by attenuating the antiapoptotic effect of inflammatory cytokines during the inflammatory process [50]. In our PI-IBS model, by 56 days PI, T. spiralis was completely absent from the intestinal mucosa but IL-17 still persisted, suggesting that increased IL-17 in the duodenum and ileum may be vital for maintaining intestinal low-grade inflammation. First, the IL-23/ IL-17 signal pathway (which regulates IL-12/IFN- $\gamma$, and drives neutrophil migration to mediate inflammation injury) has been well described [42-44]. Second, uncontrolled IL-17 responses can augment production of inflammatory factors including IL-1, IL-6, IL-8, TNF- $\alpha$, GM-CSF, and MIP-2 [44,51]. These cytokines were reported to be increased in the peripheral blood and intestinal mucosa of PI-IBS patients [20], which would alter the gut physiology and immunity of the host, causing clinical symptoms $[20,36]$.

IL-10, as a classical anti-inflammatory cytokine, decreases the inflammatory reaction through a number of mechanisms. It can diminish the production of inflammatory mediators including IL-1 $\beta$ and IFN- $\gamma$ in T cells and activate macrophages [52-54]. It also can reduce the expression of major histocompatibisblity complex class II, co-stimulating, and adhesion molecules on the surface of antigen-presenting cells [55,56]. Importantly, it can also suppress the development of mast cells [57]. In our study, IL-10 levels were decreased in the jejunum, ileum and colon of PI-IBS model mice. Because of the decreased IL-10, on one hand pro-inflammatory cytokines were much more highly expressed, resulting in intestinal low-grade inflammation persisting. On the other hand, the antigen-presenting cells maintained their function, contributing to the adaptive immune response. Furthermore, hyperplasia of mast cells may be related to the decreased IL-10 levels [57], and they can also alter homeostatic intestinal epithelial migration and barrier function $[57,58]$.

In the present study, the expression levels of IL-1 $\beta$ were not significantly different between the two groups. Further research is required to explore whether IL-1 $\beta$ levels were suppressed by anti-inflammatory cytokines other than IL-10. Although changes of the four cytokines that we measured were not found in all intestinal segments, it is reasonable to deduce that the physiology and immunity of the host may be impaired by other cytokines $[47,59]$.

\section{Conclusions}

This study indicates that visceral hypersensitivity persists after signs of chronic intestinal inflammation have disappeared. The observed long-term colonic hypersensitivity appears to be at least partially mediated by cytokines, because there is an imbalance of cytokines. The changes of cytokines in different intestinal segments may alter the imbalance between pro- and anti-inflammatory reactions within the gut. This suggests that the local low-grade inflammation and immune activation that are an important component of the pathophysiology of PI-IBS may be partly induced and maintained by cytokines. This may also explain why PI-IBS patients present with abdominal distension, abdominal pain and other clinical symptoms.

\section{Abbreviations}

PI-IBS: Post-infection irritable bowel syndrome; IL-1 $\beta$ : Interleukin-1-beta; IL-10: Interleukin-10; IL-17: Interleukin-17; IFN-ץ: Interferon-gamma; PI: Post-infection; AWR: Abdominal withdrawal reflex.

Competing interests

The authors declare that they have no competing interests.

\section{Authors' contributions}

The study was designed by $C L$ and XZ. BY carried out the animal and molecular genetic studies, research, and data analysis and wrote the paper. All authors read and approved the final manuscript. 


\section{Acknowledgments}

This work was supported by the National Natural Science Foundation of China (Grant No. 81160057). The authors thank Dr Baoquan Fu (Chinese Academy of Agricultural Sciences) for providing Trichinella.

\section{Author details}

${ }^{1}$ Department of Gastroenterology, The First Affiliated Hospital of Chongqing Medical University, Chongqing 4000 16, China. ${ }^{2}$ Department of Gastroenterology, Hainan Provincial People's Hospital, Haikou 570311, China.

Received: 5 March 2014 Accepted: 20 March 2015

Published online: 01 April 2015

\section{References}

1. Choung RS, Locke III GR. Epidemiology of IBS. Gastroenterol Clin N Am. 2011;40(1):1-10.

2. Longstreth GF, Thompson WG, Chey WD, Houghton LA, Mearin F, Spiller RC. Functional bowel disorders. Gastroenterology. 2006;130(5):1480-91.

3. Qin H-Y, Wu JY, Tong X-D, Sung JY, Xu H-X, Bian Z-X. Systematic review of animal models of post-infectious/post-inflammatory irritable bowel syndrome. J Gastroenterol. 2011;46(2):164-74.

4. Bercik P, Wang L, Verdu EF, Mao YK, Blennerhassett P, Khan WI, et al. Visceral hyperalgesia and intestinal dysmotility in a mouse model of postinfective gut dysfunction. Gastroenterology. 2004;127(1):179-87.

5. Long Y, Wang W, Wang H, Hao L, Qian W, Hou X. Characteristics of intestinal lamina propria dendritic cells in a mouse model of postinfectious irritable bowel syndrome. J Gastroenterol Hepatol. 2012;27(5):935-44.

6. Spiller R, Garsed K. Postinfectious irritable bowel syndrome. Gastroenterology. 2009;136(6):1979-88.

7. Elsenbruch S, Holtmann G, Oezcan D, Lysson A, Janssen O, Goebel MU, et al. Are there alterations of neuroendocrine and cellular immune responses to nutrients in women with irritable bowel syndrome [quest]. Am J Gastroenterol. 2004;99(4):703-10.

8. Liebregts T, Adam B, Bredack C, Röth A, Heinzel S, Lester S, et al. Immune activation in patients with irritable bowel syndrome. Gastroenterology. 2007;132(3):913-20.

9. Spiller RC, Jenkins D, Thornley JP, Hebden JM, Wright T, Skinner M, et al. Increased rectal mucosal enteroendocrine cells, T lymphocytes, and increased gut permeability following acuteCampylobacter enteritis and in post-dysenteric irritable bowel syndrome. Gut. 2000;47(6):804-11.

10. Chadwick VS, Chen W, Shu D, Paulus B, Bethwaite P, Tie A, et al. Activation of the mucosal immune system in irritable bowel syndrome. Gastroenterology. 2002;122(7):1778-83.

11. Wheatcroft J, Wakelin D, Smith A, Mahoney CR, Mawe G, Spiller R. Enterochromaffin cell hyperplasia and decreased serotonin transporter in a mouse model of postinfectious bowel dysfunction. Neurogastroenterol Motil. 2005;17(6):863-70.

12. Al-Khatib K, Lin HC. Immune activation and gut microbes in irritable bowel syndrome. Gut Liver. 2009;3(1):14-9.

13. Buhner S, Li Q, Vignali S, Barbara G, De Giorgio R, Stanghellini V, et al. Activation of human enteric neurons by supernatants of colonic biopsy specimens from patients with irritable bowel syndrome. Gastroenterology. 2009;137(4):1425-34.

14. Park JH, Rhee PL, Kim HS, Lee JH, Kim YH, Kim JJ, et al. Mucosal mast cell counts correlate with visceral hypersensitivity in patients with diarrhea predominant irritable bowel syndrome. J Gastroenterol Hepatol. 2006;21(1 Pt 1):71-8

15. Barbara G, Wang B, Stanghellini V, de Giorgio R, Cremon C, Di Nardo G, et al. Mast cell-dependent excitation of visceral-nociceptive sensory neurons in irritable bowel syndrome. Gastroenterology. 2007;132(1):26-37.

16. Kalia N, Hardcastle J, Keating C, Grasa L, Pelegrin P, Bardhan KD, et al. Intestinal secretory and absorptive function in Trichinella spiralis mouse model of postinfective gut dysfunction: role of bile acids. Gut. 2008:57(1):41-9.

17. Barbara G, Vallance BA, Collins SM. Persistent intestinal neuromuscular dysfunction after acute nematode infection in mice. Gastroenterology. 1997;113(4):1224-32.

18. Tanovic A, Fernandez E, Jimenez M. Alterations in intestinal contractility during inflammation are caused by both smooth muscle damage and specific receptor-mediated mechanisms. Croat Med J. 2006;47(2):318-26.
19. Torrents $D$, Vergara $P$. In vivo changes in the intestinal reflexes and the response to CCK in the inflamed small intestine of the rat. Am J Physiol Gastrointest Liver Physiol. 2000;279(3):G543-51.

20. Bashashati M, Rezaei N, Andrews CN, Chen C-Q, Daryani NE, Sharkey KA et al. Cytokines and irritable bowel syndrome: where do we stand? Cytokine. 2012:57(2):201-9.

21. Tjwa ET, Bradley JM, Keenan CM, Kroese A, Sharkey KA. Interleukin-1 $\beta$ activates specific populations of enteric neurons and enteric glia in the guinea pig ileum and colon. Am J Physiol Gastrointest Liver Physiol. 2003;285(6):G1268-76.

22. Kelles A, Janssens J, Tack J. IL-1 $1 \beta$ and IL-6 excite neurones and suppress cholinergic neurotransmission in the myenteric plexus of the guinea pig. Neurogastroenterol Motil. 2000;12(6):531-8.

23. Fargeas M-J, Fioramonti J, Bueno L. Central action of interleukin 1 on intestinal motility in rats: mediation by Two mechanisms. Gastroenterology-Baltimore then Philadelphia. 1993;104:377-7.

24. Shen L, Su L, Turner JR. Mechanisms and functional implications of intestinal barrier defects. Dig Dis. 2009;27(4):443-9.

25. Ferrier L, Mazelin L, Cenac N, Desreumaux P, Janin A, Emilie D, et al. Stressinduced disruption of colonic epithelial barrier: role of interferon- $\gamma$ and myosin light chain kinase in mice. Gastroenterology. 2003;125(3):795-804

26. Han X, Fink MP, Delude RL. Proinflammatory cytokines cause no [middle dot]dependent and -independent changes in expression and localization of tight junction proteins in intestinal epithelial cells. Shock. 2003;19(3):229-37.

27. Gasche C, Bakos S, Dejaco C, Tillinger W, Zakeri S, Reinisch W. IL-10 secretion and sensitivity in normal human intestine and inflammatory bowel disease. J Clin Immunol. 2000;20(5):362-70.

28. Andoh A, Takaya H, Makino J, Sato H, Bamba S, Araki Y, et al. Cooperation of interleukin-17 and interferon- $\gamma$ on chemokine secretion in human fetal intestinal epithelial cells. Clin Exp Immunol. 2001;125(1):56-63.

29. La J-H, Kim T-W, Sung T-S, Kang J-W, Kim H-J, Yang I-S. Visceral hypersensitivity and altered colonic motility after subsidence of inflammation in a rat model of colitis. World J Gastroenterol. 2003:9(12):2791-5.

30. Al-Chaer ED, Kawasaki M, Pasricha PJ. A new model of chronic visceral hypersensitivity in adult rats induced by colon irritation during postnatal development. Gastroenterology. 2000;119(5):1276-85.

31. Dieleman LA, Palmen MJ, Akol H, Bloemena E, Peña AS, Meuwissen SG, et al. Chronic experimental colitis induced by dextran sulphate sodium (DSS) is characterized by Th1 and Th2 cytokines. Clin Exp Immunol. 1998;114(3):385-91.

32. Micili SC, Goker A, Sayin O, Akokay P, Ergur BU. The effect of lipoic acid on wound healing in a full thickness uterine injury model in rats. J Mol Histol 2013:44(3):339-45.

33. Ishihara S, Tada Y, Fukuba N, Oka A, Kusunoki R, Mishima Y, et al. Pathogenesis of irritable bowel syndrome-review regarding associated infection and immune activation. Digestion. 2013;87(3):204-11.

34. Sengupta JN, Saha JK, Goyal RK. Stimulus-response function studies of esophageal mechanosensitive nociceptors in sympathetic afferents of opossum. J Neurophysiol. 1990;64(3):796-812.

35. Spiller RC. Postinfectious irritable bowel syndrome. Gastroenterology. 2003;124(6):1662-71.

36. Akiho $\mathrm{H}$, Ihara $\mathrm{E}$, Nakamura K. Low-grade inflammation plays a pivotal role in gastrointestinal dysfunction in irritable bowel syndrome. World J Gastrointest Pathophysiol. 2010;1(3):97-105.

37. Cremon C, Gargano L, Morselli-Labate AM, Santini D, Cogliandro RF, De Giorgio R, et al. Mucosal immune activation in irritable bowel syndrome: genderdependence and association with digestive symptoms. Am J Gastroenterol. 2009:104(2):392-400.

38. Ford AC, Talley NJ. Mucosal inflammation as a potential etiological factor in irritable bowel syndrome: a systematic review. J Gastroenterol. 2011:46(4):421-31.

39. Corinaldesi R, Stanghellini V, Cremon C, Gargano L, Cogliandro RF, De Giorgio R, et al. Effect of mesalazine on mucosal immune biomarkers in irritable bowel syndrome: a randomized controlled proof-of-concept study. Aliment Pharmacol Ther. 2009;30(3):245-52.

40. Feng B, La JH, Schwartz ES, Gebhart GF. Irritable bowel syndrome: methods, mechanisms, and pathophysiology. Neural and neuro-immune mechanisms of visceral hypersensitivity in irritable bowel syndrome. Am J Physiol Gastrointest Liver Physiol. 2012;302(10):8.

41. Törnblom H, Lindberg G, Nyberg B, Veress B. Full-thickness biopsy of the jejunum reveals inflammation and enteric neuropathy in irritable bowel syndrome. Gastroenterology. 2002;123(6):1972-9. 
42. Li L, Huang L, Vergis AL, Ye H, Bajwa A, Narayan V, et al. IL-17 produced by neutrophils regulates IFN- $\gamma$-mediated neutrophil migration in mouse kidney ischemia-reperfusion injury. J Clin Invest. 2010;120(1):331.

43. Langrish $\mathrm{CL}$, Chen Y, Blumenschein WM, Mattson J, Basham B, Sedgwick JD, et al. IL-23 drives a pathogenic T cell population that induces autoimmune inflammation. J Exp Med. 2005;201(2):233-40.

44. Iwakura Y, Ishigame H, Saijo S, Nakae S. Functional Specialization of Interleukin-17 Family Members. Immunity. 2011;34(2):149-62.

45. Chomarat $P$, Rissoan MC, Banchereau J, Miossec $P$. Interferon gamma inhibits interleukin 10 production by monocytes. J Exp Med. 1993;177(2):523-7.

46. Raetz M, S-h H, Wilhelm CL, Kirkland D, Benson A, Sturge CR, et al. Parasiteinduced TH1 cells and intestinal dysbiosis cooperate in IFN-[gamma]dependent elimination of Paneth cells. Nat Immunol. 2013;14(2):136-42.

47. Capaldo CT, Beeman N, Hilgarth RS, Nava P, Louis NA, Naschberger E, et al. IFN-[gamma] and TNF-[alpha]-induced GBP-1 inhibits epithelial cell proliferation through suppression of [beta]-catenin/TCF signaling. Mucosal Immunol. 2012;5(6):681-90.

48. Scharl M, Paul G, Barrett KE, McCole DF. AMP-activated Protein Kinase Mediates the Interferon-\{gamma\}-induced Decrease in Intestinal Epithelial Barrier Function. J Biol Chem. 2009;284(41):27952-63.

49. Zhu S, Qian Y. IL-17/IL-17 receptor system in autoimmune disease: mechanisms and therapeutic potential. Clin Sci. 2012;122(11):487-511.

50. Costa VS, Mattana TCC, da Silva MER. Unregulated IL-23/IL-17 immune response in autoimmune diseases. Diabetes Res Clin Pract. 2010;88(3):222-6.

51. Fossiez F, Djossou O, Chomarat P, Flores-Romo L, Ait-Yahia S, Maat C, et al. $T$ cell interleukin-17 induces stromal cells to produce proinflammatory and hematopoietic cytokines. J Exp Med. 1996;183(6):2593-603.

52. Sabat R, Grütz G, Warszawska K, Kirsch S, Witte E, Wolk K, et al. Biology of interleukin-10. Cytokine Growth Factor Rev. 2010;21(5):331-44.

53. Fiorentino DF, Zlotnik A, Mosmann TR, Howard M, O'Garra A. IL-10 inhibits cytokine production by activated macrophages. J Immunol. 1991;147(11):3815-22.

54. D'Andrea A, Aste-Amezaga M, Valiante NM, Ma X, Kubin M, Trinchieri G. Interleukin 10 (IL-10) inhibits human lymphocyte interferon gamma-production by suppressing natural killer cell stimulatory factor/L-12 synthesis in accessory cells. J Exp Med. 1993;178(3):1041-8.

55. de Waal Malefyt R, Haanen J, Spits H, Roncarolo MG, te Velde A, Figdor C, et al. Interleukin 10 (IL-10) and viral IL-10 strongly reduce antigen-specific human $T$ cell proliferation by diminishing the antigen-presenting capacity of monocytes via downregulation of class II major histocompatibility complex expression. J Exp Med. 1991;174(4):915-24.

56. Willems F, Marchant A, Delville J-P, Gérard C, Delvaux A, Velu T, et al. Interleukin-10 inhibits B7 and intercellular adhesion molecule-1 expression on human monocytes. Eur J Immunol. 1994;24(4):1007-9.

57. Speiran K, Bailey DP, Fernando J, Macey M, Barnstein B, Kolawole M, et al. Endogenous suppression of mast cell development and survival by IL-4 and IL-10. J Leukoc Biol. 2009;85(5):826-36.

58. Groschwitz KR, Ahrens R, Osterfeld H, Gurish MF, Han X, Åbrink M, et al. Mast cells regulate homeostatic intestinal epithelial migration and barrier function by a chymase/Mcpt4-dependent mechanism. Proc Natl Acad Sci. 2009;106(52):22381-6.

59. Al-Sadi R, Guo S, Ye D, Ma TY. TNF-a modulation of intestinal epithelial tight junction barrier is regulated by ERK1/2 activation of Elk-1. Am J Pathol. 2013;183(6):1871-84

\section{Submit your next manuscript to BioMed Central and take full advantage of:}

- Convenient online submission

- Thorough peer review

- No space constraints or color figure charges

- Immediate publication on acceptance

- Inclusion in PubMed, CAS, Scopus and Google Scholar

- Research which is freely available for redistribution 